\title{
Measurement of Radiation Dose in Thyroid Scintigraphy
}

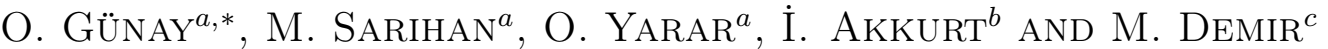 \\ ${ }^{a}$ stanbul Okan University, Vocational School of Health Services, Istanbul, Turkey \\ ${ }^{b}$ Suleyman Demirel University Department of Physics, Faculty of Art and Science, Isparta, Turkey \\ ${ }^{c}$ Istanbul University-Cerrahpasa, Cerrahpasa Faculty of Medicine, \\ Department of Nuclear Medicine, Istanbul, Turkey
}

\begin{abstract}
Determination of radiation dose rate is very important for public health and medical workers because the nuclear radiation is hazardous for all. In this study, radiation dose rate was determined after radiopharmaceutical injection for thyroid scintigraphy. Measurements of the dose rate were made at 12 different points: 25, 50, 100, and $200 \mathrm{~cm}$ from the patient's head, chest and foot level. Moreover, measurements were made at different times with GM counter to determine the dose rate decay. The amount of radioactivity injected into patients varies between $151 \mathrm{MBq}(4.1 \mathrm{Ci})$ and $192 \mathrm{MBq}(5.2 \mathrm{Ci})$, with average value of $162 \mathrm{MBq}(4.4 \mathrm{Ci})$. The radiation dose rate at $100 \mathrm{~cm}$ from the patient's chest level, after $9.16,28.83$ and $49.66 \mathrm{~min}$ of injection was calculated as $7.56,6.35$ and $4.73 \mu \mathrm{Svh}^{-1}$, respectively. After Tc-99m injection, healthcare professionals must be $1 \mathrm{~m}$ away from the patient for radiation safety. It was also emphasized that the public should not be in proximity to the patient nearer than $1 \mathrm{~m}$ for $3 \mathrm{~h}$ after injection.
\end{abstract}

DOI: 10.12693/APhysPolA.137.569

PACS/topics: Tc99m, Scintigraphy, SPECT, Thyroid

\section{Introduction}

Human beings are constantly exposed to artificial and natural radiation. The sources of artificial radiation are very diverse. One of such example could be the medical applications [1-2]. In health practices, people are often exposed to artificial radiation at radiology, radiation oncology and nuclear medicine departments. One of the most common procedures in nuclear medicine is thyroid scintigraphy.

Thyroid scintigraphy is performed for diagnosis purposes. Many conditions indicate thyroid scintigraphy, i.e., ectopic thyroid tissue, post-surgical residual tissue evaluation, examination of the neck and upper mediastinal masses, examination of the dimensions and shapes of the thyroid gland, diagnosis of nodular goiter, evaluation of thyroid functions, diagnosis of thyroid and diagnosis of hypothyroidism. In thyroid scintigraphy, Tc-99m is injected intravenously to the patient. Tc-99m emits gamma rays with the main energy of $140 \mathrm{keV}$ with half-life as short as $6 \mathrm{~h}$.

After injection, Tc- $99 \mathrm{~m}$ pertechnetate loosely binds to protein, however, most of Tc-99m pertechnetate leaves the plasma within min, and then disperses into extracellular fluid [3]. Most of the Tc-99m is excreted through the kidney, and in some special cases it is excreted with saliva, milk, and sweat [4]. Since Tc-99m is excreted from the body through the kidneys, the patient's

*corresponding author; e-mail: osman.gunay@okan.edu.tr radiation exposure is less than other nuclear investigations. In thyroid gland scan with Tc-99m pertechnetate, these tissues highly exposed to radiation are thyroid gland, stomach wall, small intestine, upper and lower intestinal wall, and urinary bladder [5-6]. People who are close to patient, like the medical team and family members, are exposed to the emanated radiation from the patient. Hence, it is of great relevance to define the level of radiation dose in this kind of scintigraphy [7-10], and in other medical units [11-15].

In this study, radiation dose rates from patients undergoing thyroid scintigraphy were investigated across time and variable distances. The patients were intravenously injected with Tc-99m in accordance with the protocol of the hospital. Then, the radiation dose rates to the environment were registered at different times and distances from the patient.

\section{Materials and methods}

This study was carried out with 25 patients (14 females, 11 males) in Istanbul Okan University hospital. Participants were randomly selected. The age of the participants was between 40 and 72 , and the average was 55.42 years. The minimum weight of the participants was $52 \mathrm{~kg}$, the maximum was $93 \mathrm{~kg}$ and the average was $77.14 \mathrm{~kg}$. The amount of radioactivity injected into patients was proportional to the patient's weight. The amount of radioactivity injected into patients varied between $151 \mathrm{MBq}(4.1 \mathrm{Ci}$ ) and $192 \mathrm{MBq}$ (5.2 Ci), and the average was $162 \mathrm{MBq}(4.4 \mathrm{Ci})$. Informed consent was obtained from the participants according to the approval of Istanbul Okan University Research Ethics Committee. 


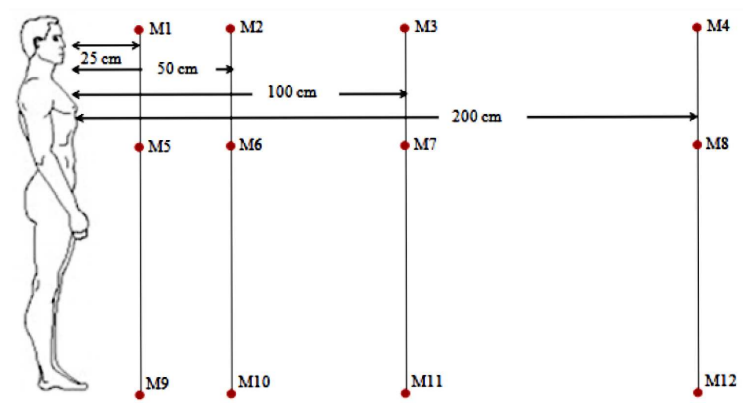

Fig. 1. Measurement regions [16].

Radiation dose rate measurements were made at 12 points from the anterior region of the patient. The GM was placed at $25,50,100,200 \mathrm{~cm}$ from the patient's head level. The measurements were repeated from the level of the patient's chest and foot (Fig. 1).

Radiation dose rate was measured at patient at different times after injection with Tc-99m. Three time intervals were considered for acquiring the measurements. The first dose rate measurements were made between 6 and 10 min after injection, with an average of $9.16 \mathrm{~min}$. Then, the measurements were repeatedly obtained between 25 and $30 \mathrm{~min}$, with an average of $28.83 \mathrm{~min}$ following injection. Radiation dose rate measurements in the third time period were made between 45 and 53 min after injection, with an average of $49.66 \mathrm{~min}$.

Radiation dose rate measurements were recorded using a GM calibrated by the Turkish Atom Energy Association (TAEK) in June 2018, (Inspector Nuclear Radiation Monitor Deluxe Dose Rate CPT.5250-0047 counter)

\section{Results and discussion}

The minimum, maximum, and mean radiation dose rate measurement results at different times and different distances from the patient's head level are shown in Table I. Following the injection, the radiation dose rate ranged from $4.61 \mu \mathrm{Svh}^{-1}$ to $9.12 \mu \mathrm{Svh}^{-1}$, with mean value of $6.23 \mu \mathrm{Svh}^{-1}$, at an average of $9.16 \mathrm{~min}$ and $100 \mathrm{~cm}$ distance from the patient's head level. In turn, the radiation dose rate ranged from $3.01 \mu \mathrm{Svh}^{-1}$ to $7.14 \mu \mathrm{Svh}^{-1}$, with a mean value of $4.46 \mu \mathrm{Svh}^{-1}$, at an average of $28.83 \mathrm{~min}$ and $100 \mathrm{~cm}$ distance from the patient's head level. In contrast, the radiation dose rate ranged from $2.51 \mu \mathrm{Svh}^{-1}$ to $6.43 \mu \mathrm{Svh}^{-1}$, with a mean value of $3.48 \mu \mathrm{Svh}^{-1}$, at an average of $49.66 \mathrm{~min}$ after the radiopharmaceutical injection, at a distance of $100 \mathrm{~cm}$ from the patient's head level.

The minimum, maximum, and mean dose rate values at different times, and distances from the patient's chest are summarised in Table II. The radiation dose rate ranged from $4.86 \mu \mathrm{Svh}^{-1}$ to $9.88 \mu \mathrm{Svh}^{-1}$, with a mean value of $7.56 \mu \mathrm{Svh}^{-1}$, at an average of $9.16 \mathrm{~min}$ after radiopharmaceutical injection, and at $100 \mathrm{~cm}$ distance from the patient's chest level. The radiation dose rate ranged from $3.97 \mu \mathrm{Svh}^{-1}$ to $8.65 \mu \mathrm{Svh}^{-1}$, with a mean value
TABLE I

Mean dose rates for different distance from patient's head level.

\begin{tabular}{c|c|c|c|c}
\hline \hline $\begin{array}{c}\text { Distance } \\
\text { from patient } \\
{[\mathrm{cm}]}\end{array}$ & $\begin{array}{c}\text { Time after } \\
\text { injection } \\
{[\mathrm{min}]}\end{array}$ & $\begin{array}{c}\text { Minimum } \\
\text { dose rate } \\
{\left[\mu \mathrm{Svh}^{-1}\right]}\end{array}$ & $\begin{array}{c}\text { Maximum } \\
\text { dose rate } \\
{\left[\mu \mathrm{Svh}^{-1}\right]}\end{array}$ & $\begin{array}{c}\text { Mean } \\
\text { dose rate } \\
{\left[\mu \mathrm{Svh}^{-1}\right]}\end{array}$ \\
\hline \multirow{2}{*}{25} & 9.16 & 13.57 & 29.12 & 19.08 \\
& 28.83 & 11.21 & 23.68 & 15.77 \\
& 49.66 & 8.64 & 18.63 & 12.63 \\
\hline \multirow{3}{*}{50} & 9.16 & 6.02 & 12.35 & 8.69 \\
& 28.83 & 5.12 & 10.67 & 7.14 \\
& 49.66 & 3.37 & 8.41 & 5.13 \\
\hline \multirow{3}{*}{100} & 9.16 & 4.61 & 9.12 & 6.23 \\
& 28.83 & 3.01 & 7.14 & 4.46 \\
& 49.66 & 2.51 & 6.43 & 3.48 \\
\hline \multirow{2}{*}{200} & 9.16 & 1.07 & 4.58 & 2.48 \\
& 28.83 & 1.01 & 3.36 & 1.69 \\
& 49.66 & 0.98 & 2.54 & 1.52
\end{tabular}

TABLE II

Mean dose rates for different distance from patient's chest level.

\begin{tabular}{c|c|c|c|c}
\hline $\begin{array}{c}\text { Distance } \\
\text { from patient } \\
{[\mathrm{cm}]}\end{array}$ & $\begin{array}{c}\text { Time after } \\
\text { injection } \\
{[\mathrm{min}]}\end{array}$ & $\begin{array}{c}\text { Minimum } \\
\text { dose rate } \\
{\left[\mu \mathrm{Svh}^{-1}\right]}\end{array}$ & $\begin{array}{c}\text { Maximum } \\
\text { dose rate } \\
{\left[\mu \mathrm{Svh}^{-1}\right]}\end{array}$ & $\begin{array}{c}\text { Mean } \\
\text { dose rate } \\
{\left[\mu \mathrm{Svh}^{-1}\right]}\end{array}$ \\
\hline \multirow{2}{*}{25} & 9.16 & 15.96 & 32.87 & 27.56 \\
& 28.83 & 13.91 & 25.48 & 24.39 \\
& 49.66 & 11.83 & 24.52 & 21.75 \\
\hline \multirow{2}{*}{50} & 9.16 & 6.48 & 14.51 & 8.91 \\
& 28.83 & 5.87 & 11.96 & 7.94 \\
& 49.66 & 4.27 & 9.73 & 6.08 \\
\hline \multirow{3}{*}{100} & 9.16 & 4.86 & 9.88 & 7.56 \\
& 28.83 & 3.97 & 8.65 & 6.35 \\
& 49.66 & 2.97 & 7.21 & 4.73 \\
\hline \multirow{2}{*}{200} & 9.16 & 1.13 & 4.96 & 3.43 \\
& 28.83 & 1.09 & 3.76 & 1.78 \\
& 49.66 & 1.02 & 2.97 & 1.58
\end{tabular}

of $6.35 \mu \mathrm{Svh}^{-1}$, at an average of $28.83 \mathrm{~min}$, and $100 \mathrm{~cm}$ distance from the patient's chest level. Whereas, the radiation dose rate was from $2.97 \mu \mathrm{Svh}^{-1}$ to $7.21 \mu \mathrm{Svh}^{-1}$, with a mean of value $4.73 \mu \mathrm{Svh}^{-1}$, at average postinjection time of $49.66 \mathrm{~min}$, and $100 \mathrm{~cm}$ distance from the patient's chest level.

The minimum, maximum, and mean radiation dose rate results at different times and at different distances from the patient's foot level are shown in Table III. The radiation dose rate ranged from $2.12 \mu \mathrm{Svh}^{-1}$ to $8.21 \mu \mathrm{Svh}^{-1}$, with a mean value of $3.91 \mu \mathrm{Svh}^{-1}$, at an average of $9.16 \mathrm{~min}$ after the radiopharmaceutical injection, and at distance of $100 \mathrm{~cm}$ from the patient's foot level. The radiation dose rate ranged from $2.01 \mu \mathrm{Svh}^{-1}$ to $6.15 \mu \mathrm{Svh}^{-1}$, with a mean value of $3.52 \mu \mathrm{Svh}^{-1}$, at an average of $28.83 \mathrm{~min}$ after the radiopharmaceutical injection, at a distance $100 \mathrm{~cm}$ from the patient's foot 
TABLE III

Mean dose rates for different distance from patient's foot level.

\begin{tabular}{c|c|c|c|c}
\hline \hline $\begin{array}{c}\text { Distance } \\
\text { from patient } \\
{[\mathrm{cm}]}\end{array}$ & $\begin{array}{c}\text { Time after } \\
\text { injection } \\
{[\mathrm{min}]}\end{array}$ & $\begin{array}{c}\text { Minimum } \\
\text { dose rate } \\
{\left[\mu \mathrm{Svh}^{-1}\right]}\end{array}$ & $\begin{array}{c}\text { Maximum } \\
\text { dose rate } \\
{\left[\mu \mathrm{Svh}^{-1}\right]}\end{array}$ & $\begin{array}{c}\text { Mean } \\
\text { dose rate } \\
{\left[\mu \mathrm{Svh}^{-1}\right]}\end{array}$ \\
\hline \multirow{2}{*}{25} & 9.16 & 10.56 & 23.61 & 16.41 \\
& 28.83 & 9.81 & 18.76 & 14.94 \\
& 49.66 & 7.23 & 14.68 & 10.69 \\
\hline \multirow{3}{*}{50} & 9.16 & 4.06 & 12.83 & 8.82 \\
& 28.83 & 3.46 & 9.12 & 4.80 \\
& 49.66 & 3.02 & 8.67 & 4.01 \\
\hline \multirow{3}{*}{100} & 9.16 & 2.12 & 8.21 & 3.91 \\
& 28.83 & 2.01 & 6.15 & 3.52 \\
& 49.66 & 1.86 & 5.42 & 3.02 \\
\hline \multirow{3}{*}{200} & 9.16 & 1.01 & 2.35 & 1.58 \\
& 28.83 & 0.92 & 3.12 & 1.33 \\
& 49.66 & 0.85 & 2.19 & 1.02
\end{tabular}

level. The radiation dose rate ranged from $1.86 \mu \mathrm{Svh}^{-1}$ to $2.35 \mu \mathrm{Svh}^{-1}$, with a mean value of $1.58 \mu \mathrm{Svh}^{-1}$, at an average of 49.66 min after the radiopharmaceutical injection, at a distance $100 \mathrm{~cm}$ from the patient's foot level.

It was found that there was a strong correlation between time and radiation dose rate at a distance of $25 \mathrm{~cm}$ from the patients' head $\left(R^{2}=0.9987\right)$, chest $\left(R^{2}=0.9993\right)$, and foot $\left(R^{2}=0.9097\right)$ levels (see Fig. 2). A strong correlation was also found between time and radiation dose rate at a distance of $50 \mathrm{~cm}$ from the patient at the head $\left(R^{2}=0.9909\right)$, chest $\left(R^{2}=0.9538\right)$, and foot $\left(R^{2}=0.9053\right)$ levels (see Fig. 3). A robust agreement was found between time and radiation dose rate at a distance of $100 \mathrm{~cm}$ from the patients' head $\left(R^{2}=0.9912\right)$, chest $\left(R^{2}=0.9810\right)$, and foot $\left(R^{2}=0.9903\right)$ levels (see Fig. 4). Additionally, the correlation between time and radiation dose rate at a distance of $200 \mathrm{~cm}$ was relatively less from the patients' head $\left(R^{2}=0.8981\right)$, chest $\left(R^{2}=0.8562\right)$, and foot $\left(R^{2}=0.9871\right)$ levels (see Fig. 5).

Radiation mean dose rates at $9.16 \mathrm{~min}$ following Tc-99m injection decreased with the distance from the patient. A strong correlation was found between the radiation dose rate and the distance from patient's head $\left(R^{2}=0.9725\right)$, chest $\left(R^{2}=0.9299\right)$, and foot $\left(R^{2}=0.9933\right)$ level (see Fig. 6). Radiation mean dose rates at 28.83 min after radiopharmaceutical injection also decreased with the distance from the patient. A strong correlation was also found between the radiation dose rate and the distance from patient's head $\left(R^{2}=0.9840\right)$, chest $\left(R^{2}=0.9435\right)$, and foot $\left(R^{2}=0.9606\right)$ level (see Fig. 7). Radiation mean dose rates at 49.66 min after radiopharmaceutical injection decreased with the distance from the patient. Further, a strong correlation was found between the radiation dose rate and the distance from patient's head $\left(R^{2}=0.9798\right)$, chest $\left(R^{2}=0.9475\right)$, and foot $\left(R^{2}=0.9589\right)$ level (see Fig. 8).

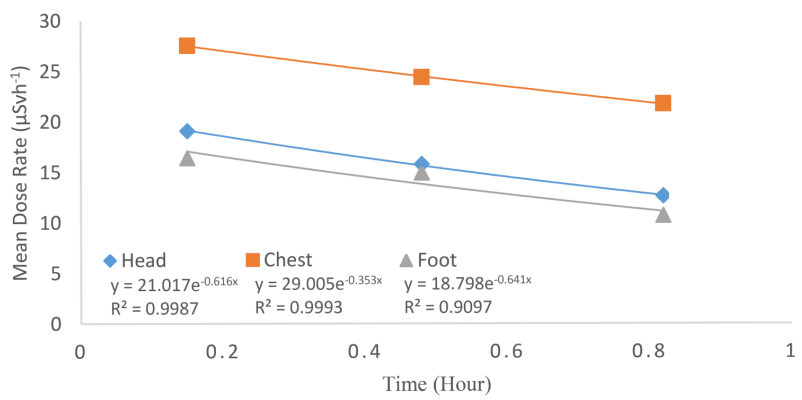

Fig. 2. Mean dose rates over time at $25 \mathrm{~cm}$ distance from the head, chest, and foot of the patients.

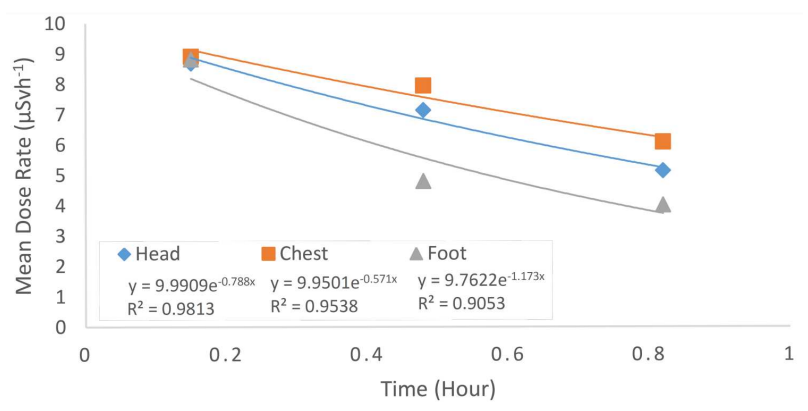

Fig. 3. Mean dose rates over time at $50 \mathrm{~cm}$ distance from the head, chest, and foot of the patients.

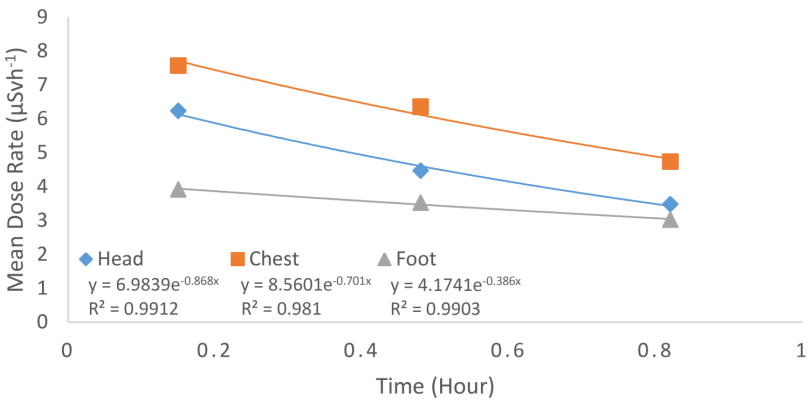

Fig. 4. Mean dose rates over time at $100 \mathrm{~cm}$ distance from the head, chest, and foot of the patients.

Many recent studies have found that the radiation dose decreases as the distance from the patient and time increase [17-21]. Günay et al. have measured the radiation dose emitted to the environment during scintigraphy in DMSA patients. In their study, an average of $168 \mathrm{MBq}$ Tc-99m was injected to the patients. At 5.07, 35.60, and 68.57 min after the injection, it was found that the radiation dose rates at $1 \mathrm{~m}$ from the patient's chest level were $5.06,4.76$, and $4.18 \mu \mathrm{Svh}^{-1}$, respectively [16]. In another study in 2019, Günay et al. determined the radiation dose rate to the environment from patients undergoing Tc-99m Sestamibi nuclear cardiac imaging. In that study, after 7.6, 36.5, and $66.4 \mathrm{~min}$ from the injection 


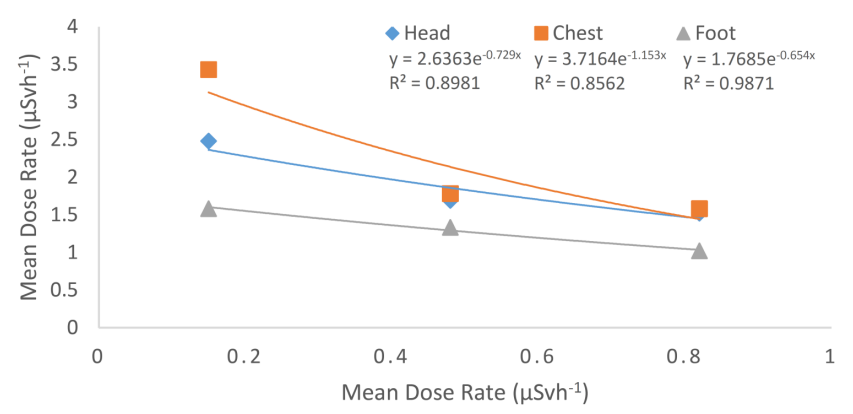

Fig. 5. Mean dose rates over time at $200 \mathrm{~cm}$ distance from the head, chest, and foot of the patients.

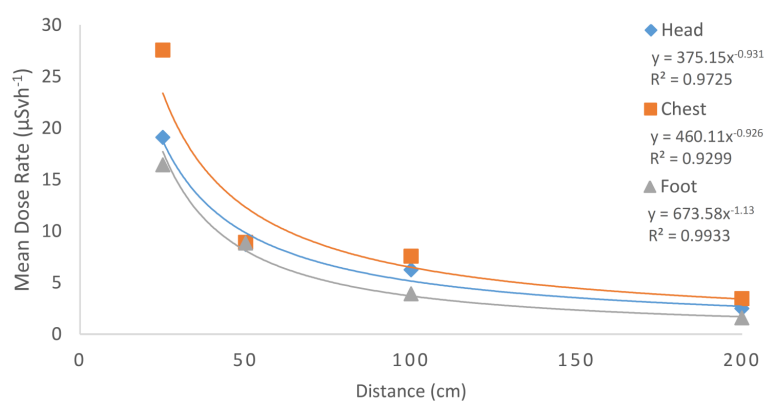

Fig. 6. Mean dose rates by distance from patients' head, chest and foot level after $9.16 \mathrm{~min}$.

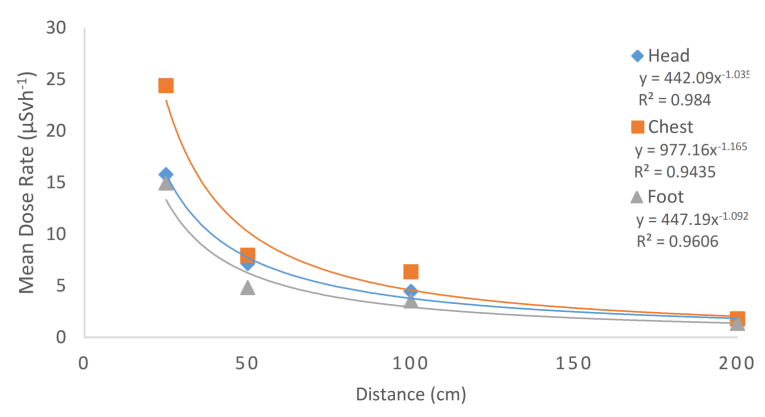

Fig. 7. Mean dose rates by distance from patients' head, chest and foot level after $28.83 \mathrm{~min}$.

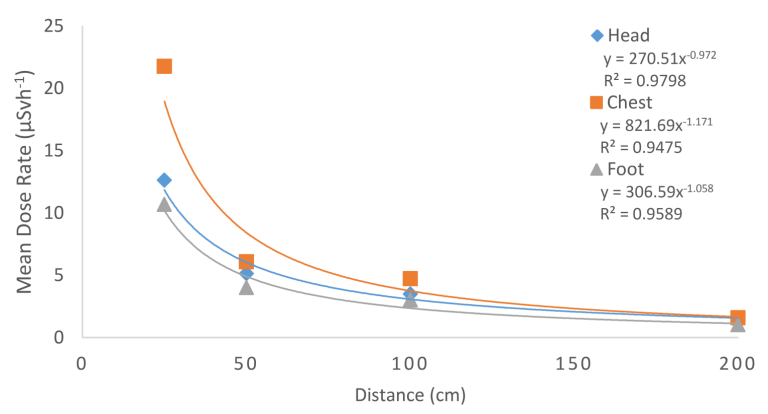

Fig. 8. Mean dose rates by distance from patients' head, chest and foot level after $49.66 \mathrm{~min}$. with an average of $391 \mathrm{MBq} \mathrm{Tc}-99 \mathrm{~m}$, the radiation dose rates at $1 \mathrm{~m}$ from the patient's chest level were 9.07, 7.93, and $7.83 \mu \mathrm{Svh}^{-1}$, respectively [22]. In our study, an average of $162 \mathrm{MBq}$ activity Tc-99m was injected to the patients. The radiation dose rates at $1 \mathrm{~m}$ from the patient's chest level decreased to $7.56,6.35$, and $4.73 \mu \mathrm{Svh}^{-1}$, after $9.16,28.83$, and $49.66 \mathrm{~min}$ of the injection, respectively. Since the radiopharmaceutical activity injected into the patient was less than Sestamibi nuclear cardiac imaging, the radiation dose rates measurements at the same time mark were lower for thyroid scintigraphy patients. Although, an equivalent activity was injected to our current patients and the DMSA patients, the emitted radiation from the patient to the environment was higher in our study. Due to the radioactivity excretion rate from the body is higher in DMSA patients.

The radiation dose rate for the healthcare workers is limited to $10 \mu \mathrm{Svh}^{-1}[23]$, and for the public to $1 \mu \mathrm{Svh}^{-1}$. In this study, the radiation dose rate at $50 \mathrm{~cm}$ from the patient's chest level was found to be $8.91 \mu \mathrm{Svh}^{-1}$ after $9.16 \mathrm{~min}$ of radiopharmaceutical injection. Therefore, radiation workers should not approach to the patients closer than $50 \mathrm{~cm}$ for longer than $9 \mathrm{~min}$ after injection. In comparison, the dose rate of $1 \mu \mathrm{Svh}^{-1}$ was estimated to be for $3 \mathrm{~h}$ after Tc-99m injection and at $1 \mathrm{~m}$ from the chest level. Thus, the appropriate protection act is to let the public away from the patients farther than $1 \mathrm{~m}$ during the first $3 \mathrm{~h}$ following the injection.

\section{Conclusions}

The radiation dose rates at $1 \mathrm{~m}$ from the patient's chest level were $7.56,6.35$, and $4.73 \mu \mathrm{Svh}^{-1}$, after 9.16, 28.83, and $49.66 \mathrm{~min}$ of injection, respectively. The healthcare workers must be $1 \mathrm{~m}$ away from the patients after Tc$99 \mathrm{~m}$ injection. It was also emphasized that the public should not approach the patients closer than $1 \mathrm{~m}$ during $3 \mathrm{~h}$ after the injection.

\section{Acknowledgments}

The authors would like to thank nuclear medicine department of İstanbul Okan University Hospital.

\section{References}

[1] L.İ. Kuru, O. Günay, H. Palacı, O. Yarar, Balı. Üniv. Fen Bil. Enst. D 21, 436 (2019).

[2] H. Palacı, O. Günay, O. Yarar, Eu. J. Sci. Tech. 14, 249 (2018).

[3] F.A. Mettler, J.R. Milton, J. Guiberteau Essentials of Nuclear Medicine Imaging, Saunders Elsevier, Philadelphia (PA) 2012, p. 607.

[4] M.T. Hays, J. Nucl. Med. 14, 331 (1973).

[5] L. Zolle, Technetium-99m Pharmaceuticals, Springer, Berlin, Heidelberg 2007, p. 7.

[6] W.M. Ali, E.Z. Dalah, L.H. Ahmed, M.M Abuzaid, J. Clinic. Diag. Res. 12(10), 1 (2018). 
[7] R. Lee, Y. So, Y.S. Song, W.W. Lee, Nucl. Med. Molec. Imag. 52, 468 (2018).

[8] M. Mert, M. Sipahi, in: Thyroid and Parathyroid Diseases Springer, 2019 p. 87.

[9] M. Bermo, S. Behnia, J. Fair, et al. Cur. Prob. Diag. Radiology 47, 324 (2018).

[10] O. Kandemir, P. Atmaca Kelkit, K. Karakuş, Nigeri. J. Clin. Pract. 20, 1510 (2017).

[11] O. GÜNay, Ö. Gündoğdu, M. Demir, M. Abuqbeitah, D. Yaşar, S. AkÖZcan, E. Kapdan, O. Yarar, IJCESEN 5, 119 (2019).

[12] Y. Yahşi çelen, H.O. Kizilkaya, IJCESEN 5, 142 (2019).

[13] O. GÜNay, M. Sarihan, E. Abamor, O. Yarar, IJCESEN 5, 86 (2019).

[14] H.O. Tekin, B. Cavli, E. Ebru Altunsoy, T. Manici, C. Ozturk, H.M. Karakas, IJCESEN 4, 37 (2018).

[15] Y. Yahşi çelen, H. Orhan Kizilkaya, IJCESEN 5, 135 (2019).
[16] O. Günay, M. Sarıhan, E. Abamor, O. Yarar, Inter. J. Comp. Exp. Sci. Eng. 5, 86 (2019).

[17] B. Cronin, P.K. Marsden, M.J. O'Doherty, Eur. J. Nucl. Med. 26, 121 (1999).

[18] M. Demir, B. Demir, H. Sayman, et al. Radiat. Prot. Dosim. 147, 528 (2011).

[19] G. Bera, M. Soret, J.A. Maisonobe et al. Méd. Nucl. 42, 45 (2018).

[20] B. Quinn, B. Holahan, J. Aime et al. Med. Phys. 39, 6071 (2012)

[21] E. Fayad, S. Maia, A. Zilnus, Med. Nucl. 39, 380 (2015).

[22] O. Günay, M. Sarıhan, O. Yarar et al. Int. J. Environ. Sci. Tech. 16, 5251 (2019).

[23] M. Demir, Nucl. Med. Semin. 3, 171 (2015). 